\title{
Green Synthesis of Silver Nanoparticle by Ficus cordata leaf Extract and Its Antibacterial Activity
}

\author{
AESA FARHAN TH. MARZUK ${ }^{1}$, HAIFAA ADNAN², NAJLAA N. HUSSEIN ${ }^{3}$, \\ AMJED MIRZA ODA ${ }^{4}$, SAIF ALDEAN KAMIL ${ }^{4}$ and MAHDI SALAH ${ }^{4}$ \\ ${ }^{1}$ Animal Production Department, Agricalture College, Al-Qasim Green University, Babylon, Iraq. \\ ${ }^{2}$ Faculty of Science, University of Babylon.Iraq. \\ ${ }^{3,4}$ Science Department, College of Basic Education, University of Babylon, Babylon, Iraq. \\ ${ }^{*}$ Corresponding author E-mail: imadbiotechnology @ gmail.com
}

http://dx.doi.org/10.13005/ojc/350340

(Received: April 21, 2019; Accepted: June 13, 2019)

\begin{abstract}
Synthesis of Silver nanoparticles (Ag-NPs) using Ficus cordata extract and evaluating of their antibacterial activity against a Staphylococcus spp and Aeromonas bacteria. Ag-NPs were prepared using aqueous extract of Ficus cordata as a green synthesis method. The spectrum of UV-Visible of the prepared Ag-NPs Shows a absorption peak at $450 \mathrm{~nm}$ due to the excitation of surface plasmon resonance (SPR). Fourier transmission infrared (FTIR) spectroscopy showed that silver nanoparticles were capped by phyto-components of Ficus cordata leaves. X-ray diffraction analysis also demonstrated that the nature of Ag-NPs were one crystalline phase. Atomic force microscope investigations of the Ag-NPs showed that the average particle size is $\sim 100 \mathrm{~nm}$. dynamic light scattering (DLS) measurement showed two kinds of distribution in a nanometric and microscale. SEM image showed Ag-NPs have a dendritic like particle shape. The result of antibacterial activities showed that Ag-NPs synthesized had an inhibiting activity against Staphylococcus spp., and Aeromonas spp., where the inhibition zone was 27 and $25 \mathrm{~mm}$ respectively.
\end{abstract}

Keywords: Silver nanoparticles, Antibacterial, FTIR, XRD, AFM.

\section{INTRODUCTION}

Nanotechnology as especially in nanoparticles scope is rapid developmental by their potential applications in many fields include that mechanics, biomedical, catalysis, magnetic sciences, energy, science, sensors and shown to be a promising antimicrobial agent ${ }^{1-3}$. Nanoparticles are clusters of atoms in range size (1-100) nm. "Nano" is a Greek word meaning a dwarf ${ }^{4}$. Chemical and physical methods are available for the synthesis of silver nanoparticle ${ }^{5}$. Green synthesis of nanoparticles utilize plant extracts has gained very importance due of the stability, synthesis fast rate of, eco-friendly and used In several applications such as chemical sense, imaging biological, antimicrobial activity, gene silencing, \& drug delivery ${ }^{6,7}$. Synthesis of silver NPs have been Reported in previous works by using and plant extracts including hibiscus, neem and black tea leaf extracts; Indian gooseberry fruit

This is an Open Access article licensed under a Creative Commons license: Attribution 4.0 International (CC- BY). Published by Oriental Scientific Publishing Company @ 2018

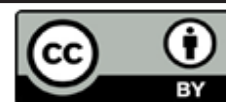


extract; camphor and aloe leaf extract ${ }^{8-10}$. Secondary metabolites of plant extracts, such as alkaloids, flavonoids and tannins are play importance role in the reduction of silver ions into silver atoms and as a stabilize agents in the preparation of NPs ${ }^{11,12}$ Characteristic of these NPs depend on the particle shape and size of the nanoparticles ${ }^{13,14}$. Ficus cordate is an important medicinal plants includes about of 20,000 species from several families. Ficus cordata belonging to family of Moraceae ${ }^{15,16}$. The utilized of Ficus are traditionally in African folk medicine in the treatment with different diseases as convulsions \& respiratory disorders ${ }^{17}$. The phytochemical compounds of Ficus are rich of prenylated lignans, flavonoids, terpenoid, alkaloids, isoflavonoid \& coumarin ${ }^{18-20}$. the authors must introduce the problem statement of the research and the aim of the work.

\section{MATERIAL AND METHODS}

\section{Synthesis of Ag-NPs}

Ficus cordata leaves were collected from Babylon area and washed with de-ionized water three times, then $10 \mathrm{~g}$ were chopped into small pieces, added to $100 \mathrm{ml}$ de-ionized water and boiled for 10 minutes. The aqueous extract was cooled and filtered thrice by Whatmane No. 1. Silver nitrate with a concentration of $(0.001,0.0025,0.005 \mathrm{M})$ purchased from British Drug House company (BDH) was added to the obtained leaves extract at ratio $2: 10$, the color of the solution was changes from pale yellow to brown color as the reduction of silver ion to Ag-NPs. The kinetic experiment was conducted by using programmable kinetic spectrophotometer at wavelength of $456 \mathrm{~nm}$.

\section{Investigations of Ag-NPs}

The UV-Visible spectrophotometer model LF 4030 Scienco (Korea) was utilized to determine the silver NPs absorption spectra at $200-800 \mathrm{~nm}$, and used Atomic force microscope model AA 3000, angstrom advanced inc. (Korea) to determine the size and morphology of Ag-NPs. Dynamic light scattering (DLS) using particle size analyzers model SALD-210 (USA) was used to measure the dynamic size distribution of Ag-NPs. Infrared spectrum was investigated by FTIR instrument using IR affinity instrument, manufactured by Shimadzu (Japan). The crystallinity of Ag-NPs were investigated by X-ray diffraction using XRD instrument model DX-2700 SSC 40 kV/30 mA, (USA), where the source Cu K $\alpha 1$ radiation $\left(\lambda=1.540562 \mathrm{~A}^{\circ}\right)$. Surface of Ag-NPs was investigated by using Scanning Electron Microscope (SEM) model Inspect 550, Netherland, operated at $25 \mathrm{kV}$.

\section{Antibacterial activity of Ag-NPs}

The antibacterial assay of Ag-NPs was done on two pathogenic Bacteria of Staphylococcus spp and Aeromonas spp., by agar well diffusion method 21 and bacteria were cultured on Muller Hinton Agar. Agar plates were prepare and wells of $3 \mathrm{~mm}$ radius were used a sterile gel borer. $100 \mu \mathrm{l}$ solution silver nanoparticles was added onto each well on all plates, then it was incubated at $37^{\circ} \mathrm{C}$ for 24 hours. Inhibition zones of bacteria were observed and measured in $\mathrm{mm}$.

\section{RESULTS AND DISCUSSION}

\section{Characterization of the synthesized Ag-NPs}

The monitoring of Ag-NPs formation is due to the color change silver ion solution after adding Ficus cordata aqueous extract. This change in the color of the solution is due to the reduction of $\mathrm{AgNO}_{3}$ by the active components that present in the plant extracts, which represent a reduction factor like antioxidant such as polyphenols, terpenoids, tannins, alkaloids and so on ${ }^{22}$. Fig. 1 indicates to UV-Vis absorption spectra for the synthesized Ag-NPs using Ficus cordata leaf extract, where the maximum absorption of Ag-NPs was at $460 \mathrm{~nm}$ due to the surface plasmone resonance effect of $\mathrm{Ag}$ NPs electron which is easily excited by the visible light. Very important result is observed that the color formation of Ag-NPs was immediately changed within few seconds and the development of the color is rapid increased when the concentration of $\mathrm{Ag}$ ion is increased. The initial concentration of $\mathrm{Ag}$ ion was studied, where at high concentration the absorbance is increased due to the high Ag ions availability and reaching at maximum absorbance at the same wavelength ${ }^{23}$.

The effect of time was studied. Fig. 2 shows the reaction kinetic of $\mathrm{Ag}$ NPs formation against to the reaction time and we found at high concentration of Ag ion the color change rapidly in the interval time of 40 seconds, where as at low concentration was $600 \mathrm{sec}$. with sigmoidal curve Shape. The results showed that at low concentration of $\mathrm{Ag}$ ion the formation of Ag-NPs is slow as it is in the nucleation 
stage followed by growth of accumulation of small particles are merged together reaching to depletion of $\mathrm{Ag}$ ion. While at high concentration of $\mathrm{Ag}$ the nucleation is very short Time stage and the growth of large particle will be dominant ${ }^{23}$.

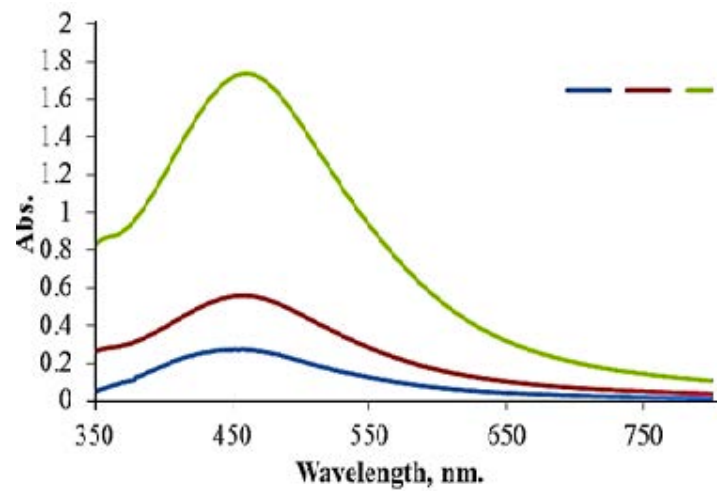

Fig. 1. UV-Visible spectra of Ag-NPs

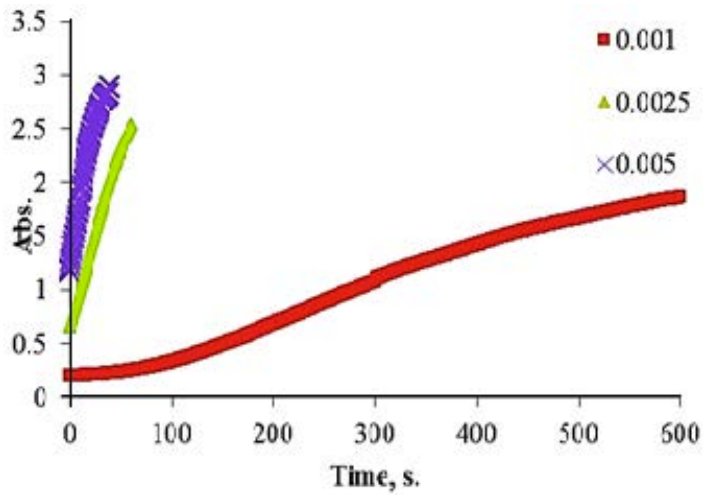

Fig. 2. Reaction Kinetic curve of Ag-NPs at different concentration

FTIR is conducted for detecting the functional groups in the Ag-NPs which is synthesized by Ficus cordata leaf extract as shown in Fig. 3. The results observed that, the band approximately equal $\left(3388.93 \mathrm{~cm}^{-1}\right)$ is related to the strtching vibration of $\mathrm{O}-\mathrm{H}$ bonds. The band at the $2983.8 \mathrm{~cm}^{-1}$ is due to existence of aliphatic band of stretching mode of $\mathrm{C}-\mathrm{H}$ bond, furthermore results of show that the bands at $1622.13 \mathrm{~cm}^{-1}$ can be assigned to stretching of $\mathrm{C}=\mathrm{C}$. Bands at $1384.89 \mathrm{~cm}^{-1}$ is related to $\mathrm{C}-\mathrm{H}$ bond bending and band $1130.29 \mathrm{~cm}^{-1}$ is related to $\mathrm{O}-\mathrm{C}-\mathrm{O}$ bending. The band at $(1074.35) \mathrm{cm}^{-1}$ is related to $\mathrm{C}-\mathrm{O}$ bonds bending, $864.11 \mathrm{~cm}^{-1}$ is related to aromatic ring and band $758.02 \mathrm{~cm}^{-1}$ is related to $\mathrm{C}-\mathrm{H}$ deformation. These functional groups are belong to phytochemical like flavonoids, terpenoids, alkaloids and like compounds ${ }^{18-20}$. This result showed that, the active components in the extract were adsorbed on the surface of Ag-NPs and this adsorption made two important factors are phytochemicals have ability to reduce the silver ion and convert them completely to Ag-NPs and this action is indicating the reduction power of the leave extract and is indicating the reduction power of the leave extract and the second factor is that, the capping activity of phyto-molecules to stabilize Ag-NPs and protect them from agglomeration and oxidation ${ }^{8,10}$.

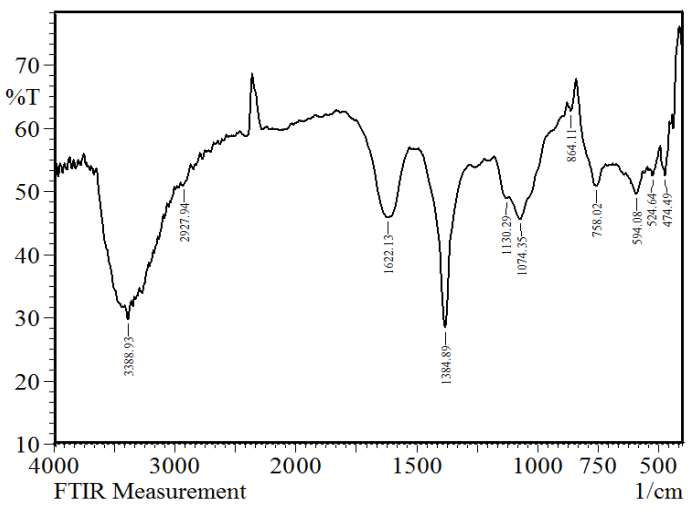

Fig. 3. FTIR spectra of Ag-NPs

Ag-NPs are analyzed by XRD technique to show the phase structure of Ag-NPs that synthesized by Ficus-cordata leaf extract and its crystallinity. $\mathrm{XRD}$ spectra is shown in Fig. 4, which is illustrate the diffraction peaks are measured in the range of $2 \theta(20-60)$, where the main peaks are at $38.42^{\circ}$ and $44.56^{\circ}$ that corresponding the planes (111) and (200) respectively for cubic face centered silver crystal. According to XRD spectrum, Ag-NPs are composed of pure silver metal without any foreign impurities contaminated the particles. Ag-NPs are stable by the capping agent represented by phytochemicals present in the extract. It was observed that the peaks of Ag NPs are broad due to the synthesis of silver on the nanometric scale and the particle size (D) can be estimated according to Scherrer's equation which is wrote on the formula of $D=0.94 \lambda / B \cos \theta$, where 0.9 is the shape constant, $\lambda=1.54060 \AA$, which is wavelength of $X$-ray beam (in the case of CuKa1), $B$ : the full width at half maximum intensity of the peak and $\theta$ : diffraction angle. $D$ value is calculated for AgNPs equal to $23 \mathrm{~nm}$, as indication of AgNPs 
that synthesized by using Ficus-cordata leaf extract are very fine particles at the nanometric scale.

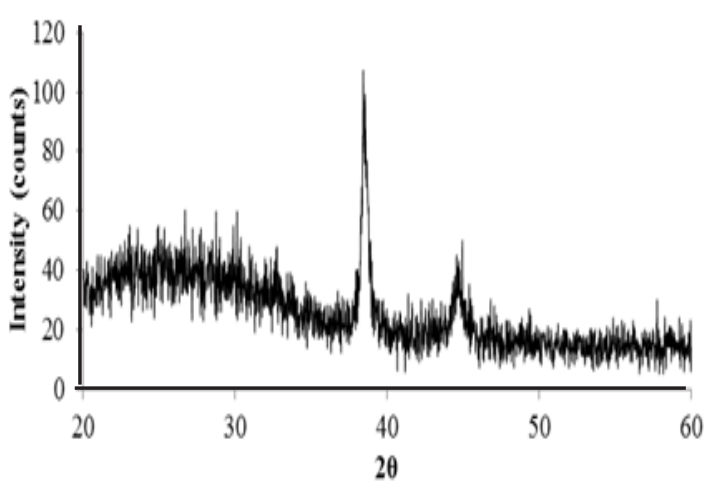

Fig. 4. XRD of silver nanoparticles

The AFM images of Ag-NPs were showed in Fig. 5 to identify the topography of the surface of the synthesized Ag-NPs by Ficus cordata leaf extract. Furthermore, average size of the synthesized particles is about $114 \mathrm{~nm}$. According to the three dimension image the sample is high roughness with diameter range $10-300 \mathrm{~nm}$ and the D50 is less than $100 \mathrm{~nm}$.

The dynamic light scattering (DLS) was applied to reveal the size of $\mathrm{Ag}$ nanoparticles as shown in Fig. 6. DLS is a technique that measure the dynamic diameter according to the scattering of laser light as a result of particle scattering light and a good tool to examine the distribution of particle size. In Fig. 6, DLS report of particle size shows different
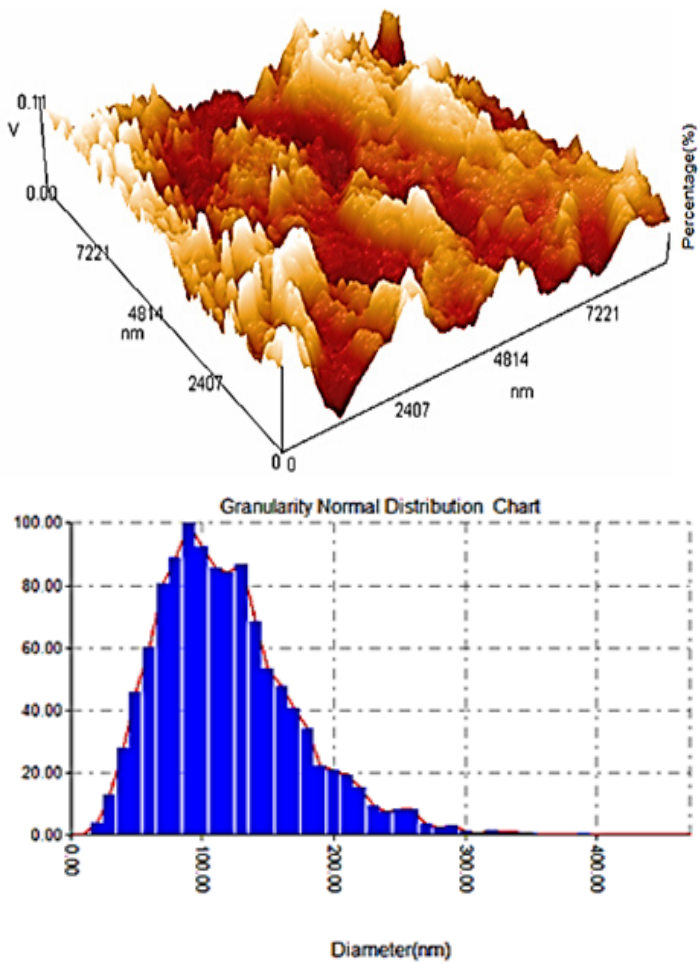

Fig. 5. three-dimensional image of Ag NPs

particle size range and three distributions curves are observed and more abaundant diameter of Ag-NPs is $150 \mathrm{~nm}$ and the other are large particles due to the agglomeration of $\mathrm{Ag}-\mathrm{NPs}$ that may result from the high rate of reaction to form Ag-NPs or adsorption of high concentration of molecular phytochemicals which cause enlargement of dynamic diameter ${ }^{25}$.

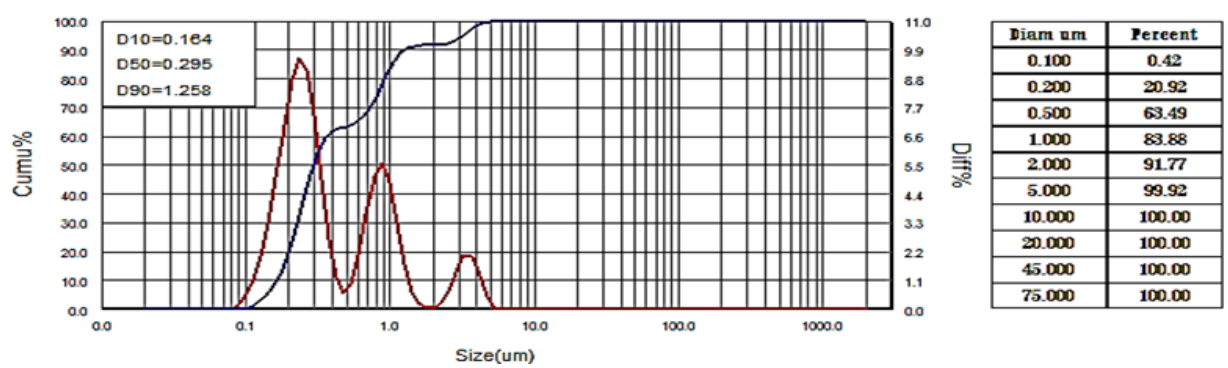

Fig. 6. Distribution of Ag NPs were synthesized by Ficus cordata leaf extract

Ag NPs were tested by SEM instrument as shown in Fig. 7. The formed Ag NPs have a dendritic like shape and it may be due to the using of Ficus cordata leaf extract as a reducing and capping agent. According to formation of Ag-NPs in the solution has fast rate and this mean the crystallization is dominant more than nucleation stage. This fast reaction made Ag-NPs does not allow the first nucleus to be stable but merge with other Ag-NPs nucleus forming a large crystal with regular shape. This may explain why in AFM and DLS measurements, the diameter range was a wide distribution and DLS shows the presence of three distributions curves.

\section{Antibacterial activity of Ag-NPs}

Ag-NPs are known as effective action for 
bacteria inhibition and interested as alternative bactericidal agent for resistant bacteria against antibiotics. In this study we demonstrate the ability of Ag-NPs agaist pathogenic bacteria like Staphylococcus spp and Aeromonas spp by using diffusion well method. In Fig. 8 two photographic pictures of petri dishes for the two kinds of Staphylococcus spp and Aeromonas spp under our study showed that $100 \mathrm{~mL}$ of $\mathrm{Ag}-\mathrm{NPs}$ solution in four wells were enough for inhibition. Each Petri dish engraved in to four wells and obviously all wells had the same inhibition zone approximately. This result is an indication of Ag-NPs have antibacterial activity. This activity is related to the particle at the nanometric scale have ability to kill bacteria by understood michanism. This action may be explaind according to recent studies that related the bioactive of Ag-NPs against bactria as following: due to Ag-NPs have small scale lower than bateria and can be attached to bacteria membrane causing the nature and premeability. Ag-NPs are disturbing the function of membrane and leak the diffusion of cellular fluid then lead to death. Another mechanism is depen on the pentration of Ag-NPs inside bacteria and undergo a cytoplasmic reaction and free sliver ion which is defect the enzyme in the -SH linkage leading to lekage of resperition reaction leading to bacteria death. Also, Ag-NPs can damage DNA, where which capable to penetrate bacteria and fungi; furthermore the damage by reacting with S-residues and P-residues in DNA ${ }^{26,28}$. According to inhibition zone, Ag-NPs have high activity against Staphylococcus spp and Aeromonas spp. The average of inhibition zone was calculated and equal to 27 and 25 for Staphylococcus spp and Aeromonas spp. respectively as shown in Table 1.

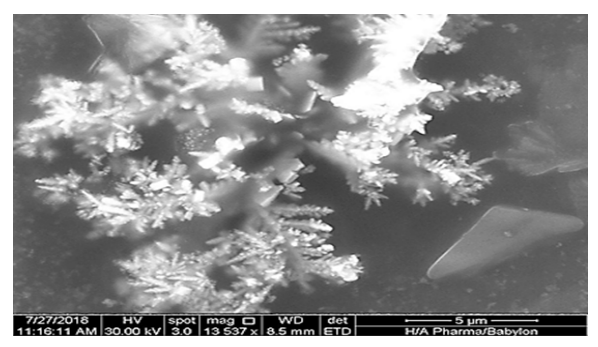

Fig. 7. SEM image of Ag-NPs

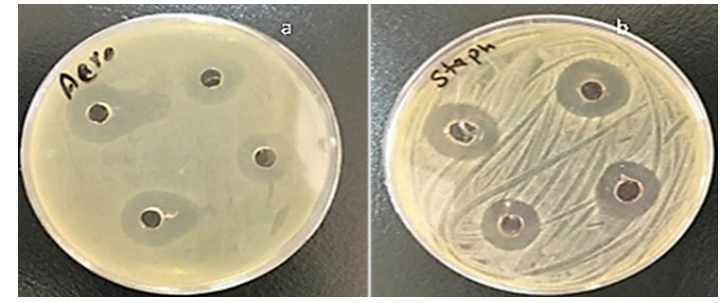

Fig. 8. Photographic picture of Aeromonas spp (a) and Staphylococcus spp (b) in Petri dishes culture

Table 1: Antibacterial activity of Ag nano-particles

\begin{tabular}{cc}
\hline Bacterial isolate & Inhibition zone rate $(\mathrm{mm})$ \\
\hline Staphylococcus spp. & 27 \\
Aeromonas spp. & 25 \\
\hline
\end{tabular}

\section{CONCLUSION}

Ag-NPs were prepared successfully using green synthesis by Ficus cordata leaf extract. Ag-NPs were formed after red color has SPR at $465 \mathrm{~nm}$. Silver ion reduced to Ag-Nps easily in few seconds and the reaction kinetic obey sigmoidal curve. FTIR analysis showed the adsorption of active components Ficus cordata leaf extract and work as capping and stabilizer. XRD spectrum describe the only phase is belong to faced centered cubic crystal as an indication of metallic Ag-NPs formation. AFM and DLS measurement were demonstrated that Ag-NPs have a particle size less than $100 \mathrm{~nm}$. SEM image showed that Ag-NPs were in crystalline form with dendritic form. Also, Ag-NPs have antibacterial activity against Staphylococcus spp, Aeromonas spp with inhibition zone around 27 and 25 respectively.

\section{ACKNOWLEDGEMENT}

I would like to express my deep appreciation to head of department of Science and Dean of Basic Education College for facilitate all tests and their support to achieve this research.

\section{Conflict of interest}

All authors are surely to declare that there is no conflict of interest of this research.

\section{REFERENCES}

1. Sulaiman, G.M., Mohammed, W.H., Marzoog, T.R., Al-Amiery, A.A.A., Kadhum, A.A.H. and Mohamad, A.B. Asian Pacific journal of tropical biomedicine., 2013, 3(1), 58-63. 
2. Araujo, E.A., Andrade, N.J., da SILVA, L.H.M., Bernardes, P.C., Teixeira, A.V.D.C., de SÁ, J.P.N., Fialho Jr, J.F.Q. and Fernandes, P.E. Journal of food protection., 2012, 75(4), 701-705.

3. Ahmed, M.J., Murtaza, G., Mehmood, A. and Bhatti, T. M. Materials Letters., 2015, 153, 10-13.

4. Rai, M., Yadav, A and Gade, A., Biotechnology advances., 2009, 27(1), 76-83.

5. Gutierrez-Wing, C., Esparza, R., VargasHernandez, C., Garcia, M.F. and Jose-Yacaman, M., Nanoscale., 2012, 4(7), 2281-2287.

6. Wei, D. and Qian, W. Colloids and Surfaces B: Biointerfaces., 2008, 62(1), 136-142.

7. Anbukkarasi, M.; Thomas, P.A.; Sheu, J.R. and Geraldine, P. Biomedicine \& Pharmacotherapy., 2017, 91, 467-475.

8. Njagi, E.C., Huang, H., Stafford, L., Genuino, H., Galindo, H.M., Collins, J.B., Hoag, G.E. and Suib, S.L. Langmuir., 2010, 27(1), 264-271.

9. X. C. Huang, H. Lin, Y.Y. Chen. Silk., 2009, 26-29.

10. Zhang, Y., Cheng, X., Zhang, Y., Xue, $\mathrm{X}$. and $\mathrm{Fu}, \mathrm{Y}$. Colloids and Surfaces $\mathrm{A}$ : Physicochemical and Engineering Aspects., 2013, 423, 63-68.

11. Prabhu, S. and Poulose, E.K. International nano letters., 2012, 2(1), 32.

12. Kumar, V. and Yadav, S.K. Journal of Chemical Technology \& Biotechnology., 2009, 84(2), 151-157.

13. Kumar, V.G., Gokavarapu, S.D., Rajeswari, A., Dhas, T.S., Karthick, V., Kapadia, Z., Shrestha, T., Barathy, I.A., Roy, A. and Sinha, S. Colloids and Surfaces B: Biointerfaces., 2011, 87(1), 159-163.

14. Giljohann, D.A., Seferos, D.S., Daniel, W.L., Massich, M.D., Patel, P.C. and Mirkin, C.A. Angewandte Chemie International Edition., 2010, 49(19), 3280-3294.

15. Kuete, V., Ngameni, B., Simo, C.F., Tankeu, R.K., Ngadjui, B.T., Meyer, J.J.M., Lall, N. and Kuiate, J.R. Journal of ethnopharmacology.,
2008, 120(1), 17-24.

16. Poumale, H.M., Kengap, R.T., Tchouankeu, J.C., Keumedjio, F., Laatsch, H. and Ngadjui, B.T. Zeitschrift fuer Naturforschung B., 2008, 63(11), 1335-1338.

17. Wakeel, O.K., Aziba, P.I., Ashorobi, R.B., Umukoro, S., Aderibigbe, A.O. and Awe, E.O. African Journal of Biomedical Research., 2004, 7(2).1450-1461.

18. Kuo, Y.H. and Li, Y.C. Journal of the Chinese Chemical Society., 1997, 44(3), 321-325.

19. Damu, A.G., Kuo, P.C., Shi, L.S., Li, C.Y., Kuoh, C.S., Wu, P.L. and Wu, T.S. Journal of natural products., 2005, 68(7), 1071-1075.

20. Chiang, Y.M., Chang, J.Y., Kuo, C.C., Chang, C.Y.and Kuo, Y.H. Phytochemistry., 2005, 66(4), 495-501.

21. Jena, S.; Singh, R.K.; Panigrahi, B.; Suar, M. and Mandal, D. Journal of Photochemistry and Photobiology B: Biology., 2016, 164, 306-313.

22. Gopinath, V.; MubarakAli, D.; Priyadarshini, S.; Priyadharsshini, N.M.; Thajuddin, N. and Velusamy, P. Colloids and Surfaces B: Biointerfaces., 2012, 96, 69-74.

23. Satyabrata Si and Tarun K. Chem. Eur. J., 2007, 13, $3160-3168$

24. Vilchis-Nestor, A.R., Sánchez-Mendieta, V., Camacho-López, M.A., Gómez-Espinosa, R.M., Camacho-López, M.A. and ArenasAlatorre, J. A. Materials Letters., 2008, 62 (17-18), 3103-3105.

25. Huang, J., Li, Q., Sun, D., Lu, Y., Su, Y., Yang, X., Hong, J. Nanotechnology., 2007, 18(10), 105104.

26. Salomoni, R., Léo, P., Montemor, A.F., Rinaldi, B.G. and Rodrigues, M.F.A. Nanotechnology, science and applications., 2017, 10, 115.

27. Krishnaraj, C., Ramachandran, R., Mohan, K. and Kalaichelvan, P.T. Spectrochimica Acta Part A: Molecular and Biomolecular Spectroscopy., 2012, 93, 95-99.

28. Klasen, H. J. Burns., 2000, 26(2), 117-130. 